\title{
Alternativas para contenção do processo de valorização da taxa de câmbio brasileira
}

\author{
Marcelo Luiz Curado*
}

Luciano Nakabashi**

\section{Principais causas da valorização do Real}

Recentemente o país vem experimentando um processo de valorização de sua moeda em relação ao dólar. O Banco Central do Brasil vem realizando, sem muito êxito, compras significativas de dólares no mercado de câmbio com objetivo de conter o processo de valorização do real. Uma pergunta relevante que pode ser feita é: quais os elementos que explicam esta valorização de nossa moeda?

Existem três elementos principais que podem explicar esse processo:

1) Em grande medida, nosso superávit comercial - fonte importante de dólares que pressionam pela valorização do real - é o resultado deste processo de expansão da economia mundial e do ciclo de valorização dos insumos em nível internacional.

2) A melhoria nos indicadores macroeconômicos é outro fator que tem contribuído para a entrada de dólares no país, particularmente para a entrada de investimento estrangeiro direto (IED). O mês de março de 2007 registrou um recorde histórico da entrada destes investimentos.

3) A taxa de juros, a maior taxa básica real do mundo, é outro fator de pressão sobre o mercado de câmbio. Ao manter o diferencial de juros elevados, o Banco Central atrai investimentos de curto prazo, pressionando ainda mais o mercado de câmbio.

Em suma, a combinação de superávits comerciais com a entrada de capitais de curto e longo prazo tem promovido uma ampliação da oferta de dólares no mercado cambial brasileiro, o que tem contribuído de forma decisiva para a queda do valor da moeda norteamericana.

\subsection{O superávit da balança comercial}

Em relação ao primeiro motivo mencionado, o intenso ritmo de crescimento da economia norte-americana e da Ásia, com destaque para a China, tem garantido a manutenção de patamares elevados de demanda por insumos básicos, elevando o preço das commodities em nível internacional (FIESP, 2006).

\footnotetext{
* Doutor em economia pela UNICAMP, chefe e professor adjunto do departamento de economia da UFPR. Endereço eletrônico: mcurado@ufpr.br

** Doutor em economia pelo CEDEPLAR/UFMG e professor adjunto do departamento de economia da UFPR. Endereço Eletrônico: luciano.nakabashi@ufpr.br
} 
Pelo gráfico 1 é notável o bom desempenho do setor exportador, principalmente a partir de 2002:

Gráfico 1. Importações, exportações e balança comercial - 01/2001 a 05/2007

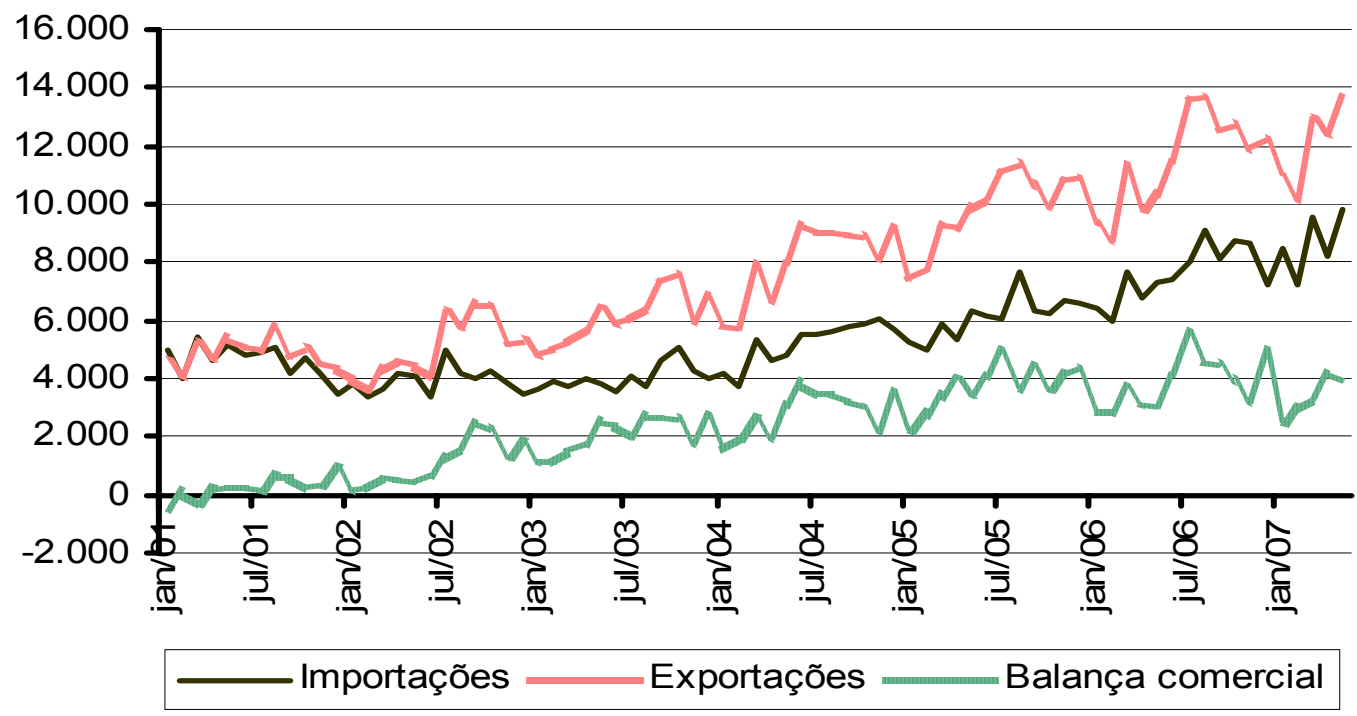

Fonte: Boletim do Banco Central do Brasil

Notas: Importações (FOB) - US\$ (milhões) - BCB Boletim/BP, Exportações (FOB) - US\$ (milhões)

- BCB Boletim/BP e Balança comercial (FOB) - saldo - US\$ (milhões) - BCB Boletim/BP.

Desse modo, a relação de causalidade entre câmbio e saldo da balança comercial brasileira vai do bom desempenho do segmento exportador de commodities e produtos industriais básicos para a valorização cambial. Isso explica o fato do saldo da balança comercial continuar favorável apesar do processo de valorização cambial.

No entanto, considerando os outros segmentos exportadores, pelo menos no caso do intensivo em mão-de-obra, a relação de causalidade vai da valorização cambial para o desempenho das exportações, ou seja, por ser um segmento que depende de preços baixos para ser competitivo, ele vem perdendo espaço na pauta exportadora (Nakabashi, Cruz e Scatolin, 2007).

Adicionalmente, cabe notar que, apesar do bom desempenho do setor exportador, o volume das importações está aumentando mais rapidamente do que o montante de exportações e reduzindo, desse modo, o saldo da balança comercial, principalmente a partir de meados de 2006. 


\subsection{O Investimento Estrangeiro Direto (IED)}

O investimento estrangeiro direto (IED), após uma perda de importância nos anos 2002 e 2003 voltou a ganhar importância a partir de 2004, sendo outra importante via de elevação da oferta de divisas, como pode ser visto no gráfico 2:

Gráfico 2. Investimento estrangeiro direto - 01/2001 a 03/2007

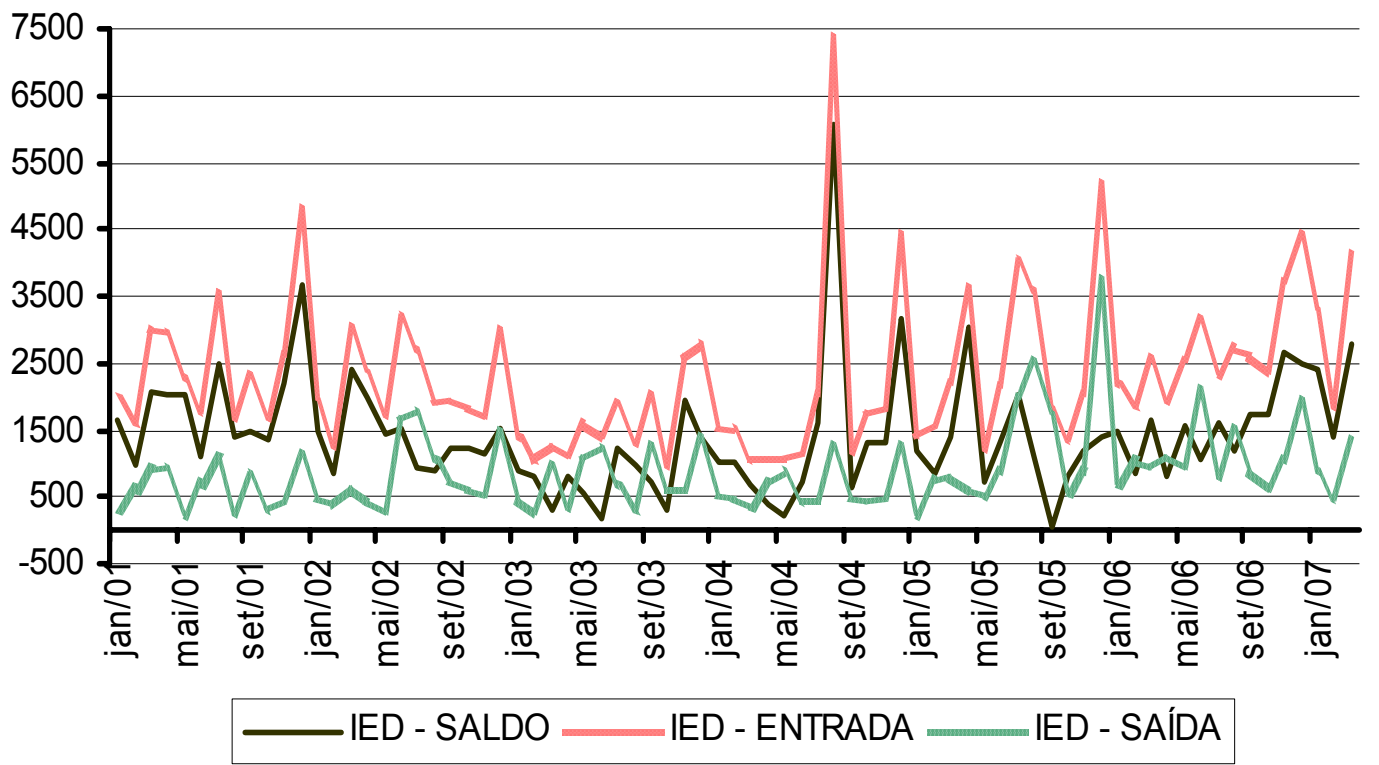

Fonte: Boletim do Banco Central do Brasil

Notas: IED SALDO é a conta financeira - investimentos diretos - estrangeiro no país - US\$ (milhões) - BCB Boletim/BP, IED ENTRADA é a conta financeira - investimentos diretos - estrangeiro no país - ingressos - US\$ (milhões) - BCB Boletim/BP e IED SAÍDA é a conta financeira investimentos diretos - estrangeiro no país - saídas - US\$ (milhões). Todas as séries seguem a metodologia do Manual do Balanço de Pagamentos do FMI.

O bom desempenho do IED no país parece, em grande medida, responder a fatores internos da economia. Como ressaltado por Rodrick (1999): "Much, if not most, of the correlation between the presence of [FDI] and superior performance seems to be driven by reverse causality: multinational enterprises tend to locate in the more productive and profitable economies" (p.37).

Em um estudo realizado por Schneider e Frey (1985), os autores encontram evidências de que fatores econômicos como o crescimento do PIB, a taxa de inflação, o desempenho do Balanço de Pagamentos, o custo salarial dos trabalhadores e a qualificação da força de trabalho e fatores de instabilidade política são variáveis relevantes na determinação do montante de IED. 


\subsection{O nível da taxa de juros}

$\mathrm{Na}$ década de 90 e começo de 2000, a taxa de juros foi um importante instrumento utilizado para conter fuga de capitais em períodos de crise. O último episódio se iniciou no final de 2002 e a taxa real de juros chegou a ficar acima dos $18 \%$ a.a. ${ }^{10}$ em meados de 2003 , como podemos ver no gráfico 3. Assim, devido a recorrentes crises no balanço de pagamentos, os formuladores de política monetária se sentiram obrigados a manter os juros em patamares elevados.

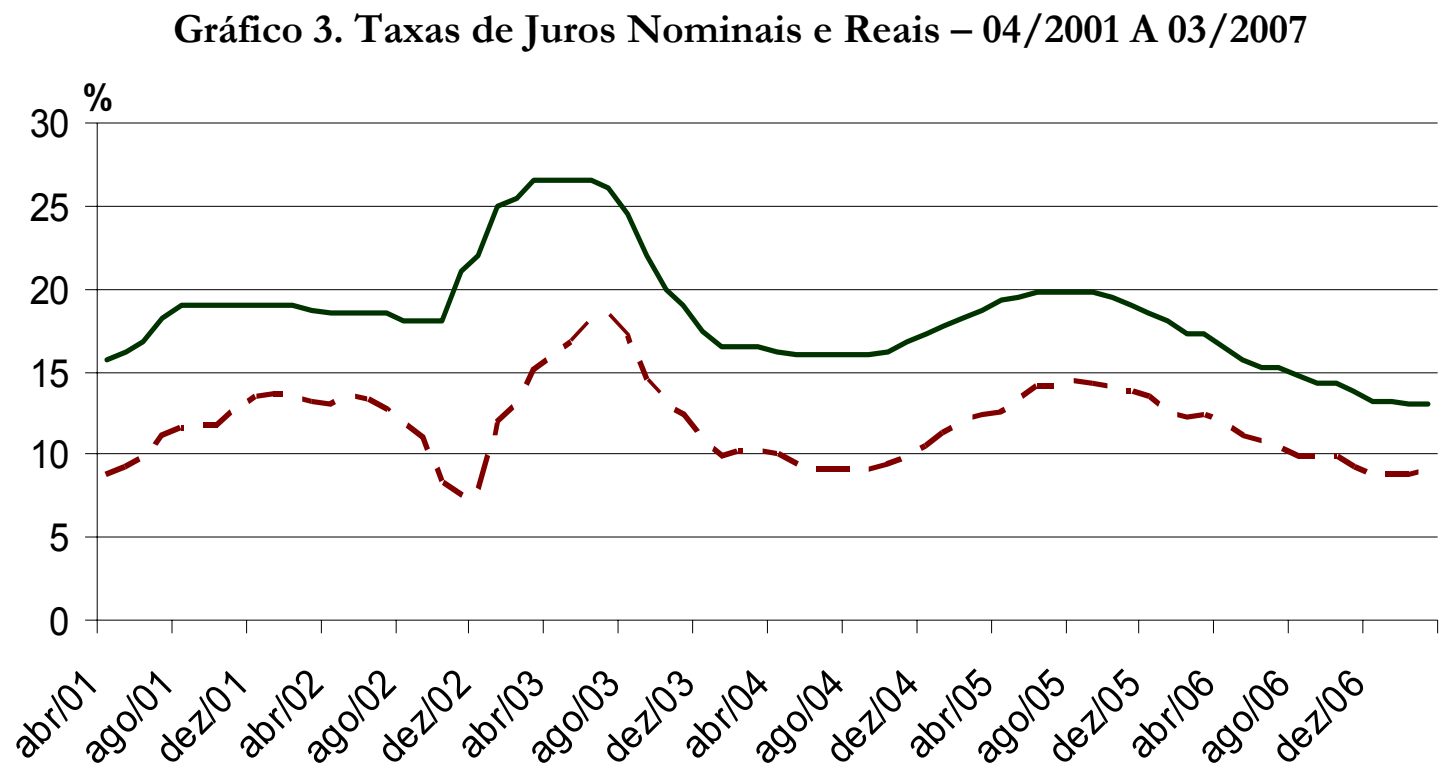

\section{— Selic fixada pelo COPOM - - Juros Reais (ex-ante) COPOM}

Fonte: elaboração própria a partir dos dados do Banco Central do Brasil

Notas: a primeira série (taxa de juros nominal) é a taxa de juros - Selic - fixada pelo Comitê de Política Monetária (Copom) e a segunda (taxa de juros reais) é a primeira série descontada pela expectativa média de inflação - IPCA - taxa acumulada para os próximos doze meses.

Após esse período, a taxa de juros foi utilizada, sobretudo, como um instrumento para a realização de ajustes inflacionários de modo a satisfazer as metas para inflação estabelecidas pelo Banco Central. Esse fato aliado ao elevado nível da dívida externa explicam boa parte da continuidade da taxa de juros em um patamar elevado em relação aos demais países.

O problema é que a manutenção da taxa de juros em patamares elevados para controlar a inflação acaba por gerar um círculo vicioso, pois ela (a manutenção dos juros em

\footnotetext{
10 Selic fixada pelo COPOM descontada pela expectativa de inflação dos próximos 12 meses (ambas do Banco Central do Brasil).
} 
um nível elevado) provoca uma tendência de crescimento da dívida pública que, por sua vez, cria maiores pressões para mantê-la em patamares ainda mais altos.

\subsection{A desvalorização do Dólar}

Estes elementos, embora relevantes, não esgotam a questão. É fundamental lembrar que a desvalorização da moeda norte-americana não é um fenômeno local. Pelo contrário, há uma tendência mundial de desvalorização do dólar.

Os Estados Unidos têm sistematicamente registrado desequilíbrios em sua balança comercial, em seu saldo em transações correntes e em seu resultado global do balanço de pagamentos. Este desequilíbrio, no entanto, não se constitui, ao menos por enquanto, num problema para a economia americana.

Os norte-americanos imprimem o padrão monetário internacional. Não podemos esquecer que a maior parte das reservas dos Bancos Centrais de todo o mundo é formada por dólares. Isto permite que eles paguem por esse excesso de gasto com a moeda por eles impressa.

A ampliação da liquidez internacional em dólares é o efeito colateral deste excesso de gastos. Ao inundar o mundo com dólares, os norte-americanos contribuem de forma decisiva para o processo de desvalorização de sua moeda.

A valorização do real, assim como de outras moedas, decorre, em parte, de um desequilíbrio estrutural do balanço de pagamentos norte-americano ou, como disse o brilhante economista Barry Eichengreen, decorre do fato de os norte-americanos "viverem além de seus meios".

No entanto, o real vem apresentando um processo de valorização em relação ao dólar em um nível superior ao registrado pelas moedas de outros países, ou seja, a nossa moeda está se valorizando em relação às demais.

Utilizando dados referentes à taxa de câmbio efetiva real dos produtos da indústria de transformação exportados (TCER_IPA-IT) ${ }^{11}$ e dos produtos exportados (TCER_IPA-

\footnotetext{
11 "Medida da competitividade das exportações brasileiras calculada pela média ponderada do índice de paridade do poder de compra dos 16 maiores parceiros comerciais do Brasil. A paridade do poder de compra é definida pelo quociente entre a taxa de câmbio nominal (em R \$/unidade de moeda estrangeira) e a relação entre o Indice de Preço por Atacado (IPA) do pais em caso e o Indice de Preços por Atacado da indústria de tranformação (IPA-IT/FGV) do Brasil. As ponderações utilizadas são as participações de cada parceiro no total das exportações brasileiras de manufaturados em 2001.” (IPEADATA, 2007).
} 
$\mathrm{OG})^{12}$, o processo de valorização do real em relação aos principais mercados de destino de nossas exportações é evidente:

\section{Gráfico 4. Taxa efetiva do câmbio real - 01/1980 a 04/2007}

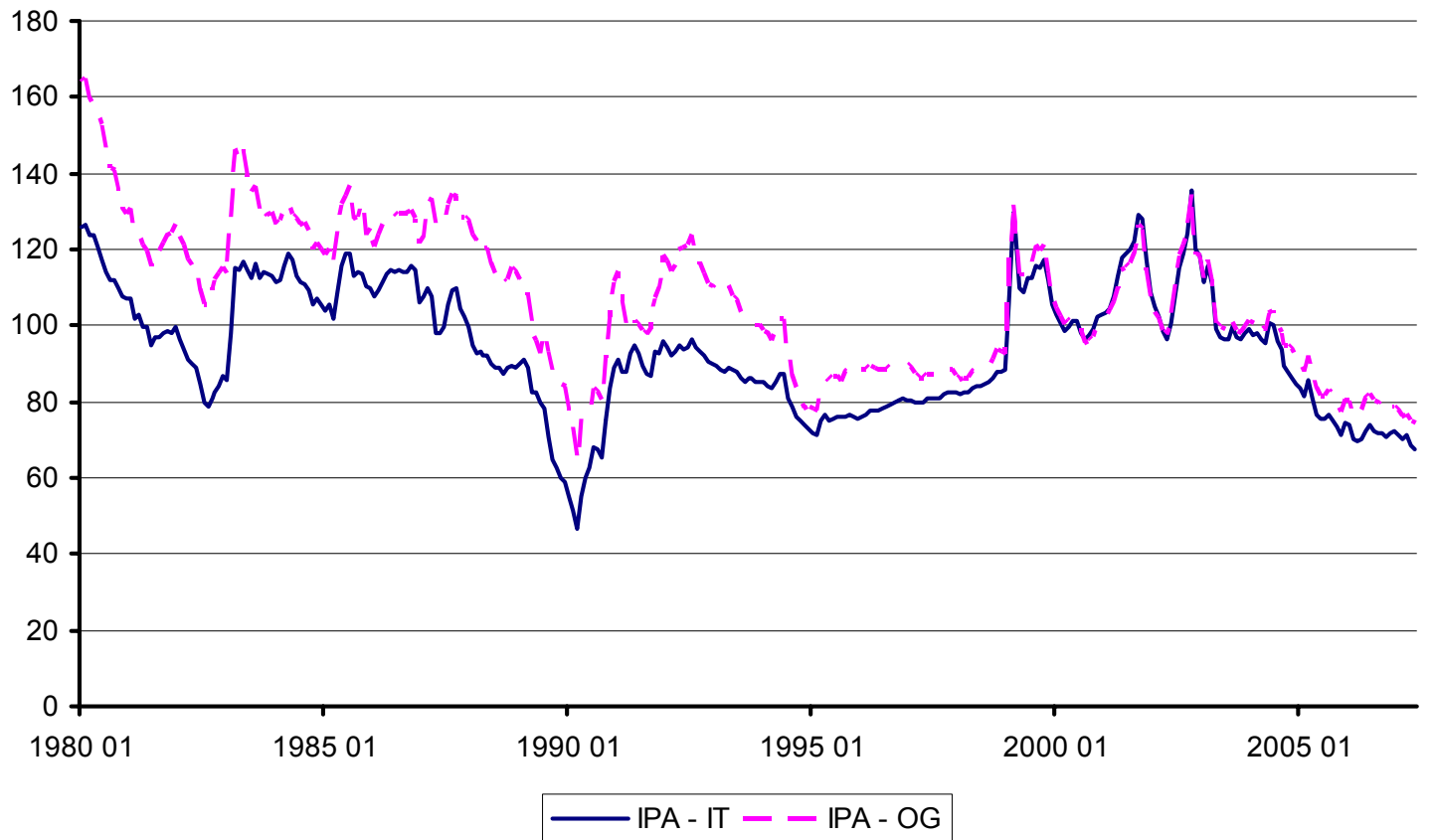

Fonte: Elaboração própria a partir de dados do IPEA.

Comparando o período pós-implantação do Plano Real com o atual, no gráfico 4, podemos observar que nesse último a moeda brasileira se apresenta ainda mais valorizada do que no primeiro. Isso acontece tanto para as exportações de uma forma geral quanto para as exportações da indústria de transformação.

\section{Conseqüências da valorização do Real}

Mas qual seria a relevância do processo de valorização do Real? Por ser apenas um preço que equilibra as contas externas do país, não seria prudente deixar que o mercado encontrasse o seu valor de equilíbrio?

Se a estrutura produtiva é importante na determinação do desempenho da economia, uma mudança em sua estrutura devido à valorização cambial poderia trazer conseqüências negativas no longo prazo a depender do padrão de especialização.

\footnotetext{
12 "Medida da competitividade das exportações brasileiras calculada pela média ponderada do índice de paridade do poder de compra dos 16 maiores parceiros comerciais do Brasil. A paridade do poder de compra é definida pelo quociente entre a taxa de câmbio nominal (em R \$/unidade de moeda estrangeira) e a relação entre o Indice de Preço por Atacado (IPA) do pais em caso e o Indice de Preços por Atacado oferta global (IPA-OG/FGV) do Brasil. As ponderações utilizadas são as participações de cada parceiro no total das exportações brasileiras em 2001." (IPEADATA, 2007).
} 
Alguns estudos, como feijó et al. (2005) em um relatório preparado para o Instituto de Estudos para o Desenvolvimento Industrial (IEDI), o relatório Trade and Development Report, 2003 da Unctad e Palma (2005), apresentam evidências de que o Brasil estaria mudando sua estrutura produtiva, com a indústria de transformação perdendo participação no emprego e no PIB.

Palma (2005) sugere que alguns países da América Latina, inclusive o Brasil, começaram a passar por um processo acelerado de "desindustrialização" a partir dos anos 80 devido a algumas mudanças ocorridas no cenário internacional e às políticas macroeconômicas adotadas por eles.

Segundo Scatolin et al. (2007) há evidências de que o processo de desindustrialização está ocorrendo no Brasil atualmente devido, principalmente, à valorização da taxa de câmbio. De fato, como podemos ver no gráfico 5, é evidente o fraco desempenho do PIB da indústria e do PIB da indústria de transformação em relação à taxa de variação do PIB da economia como um todo nos anos de 2005 e 2006:

\section{Gráfico 5. Diferença na taxa de variação do PIB da indústria e do PIB da indústria} de transformação em relação à taxa de variação do PIB total - 1971 a 2006.

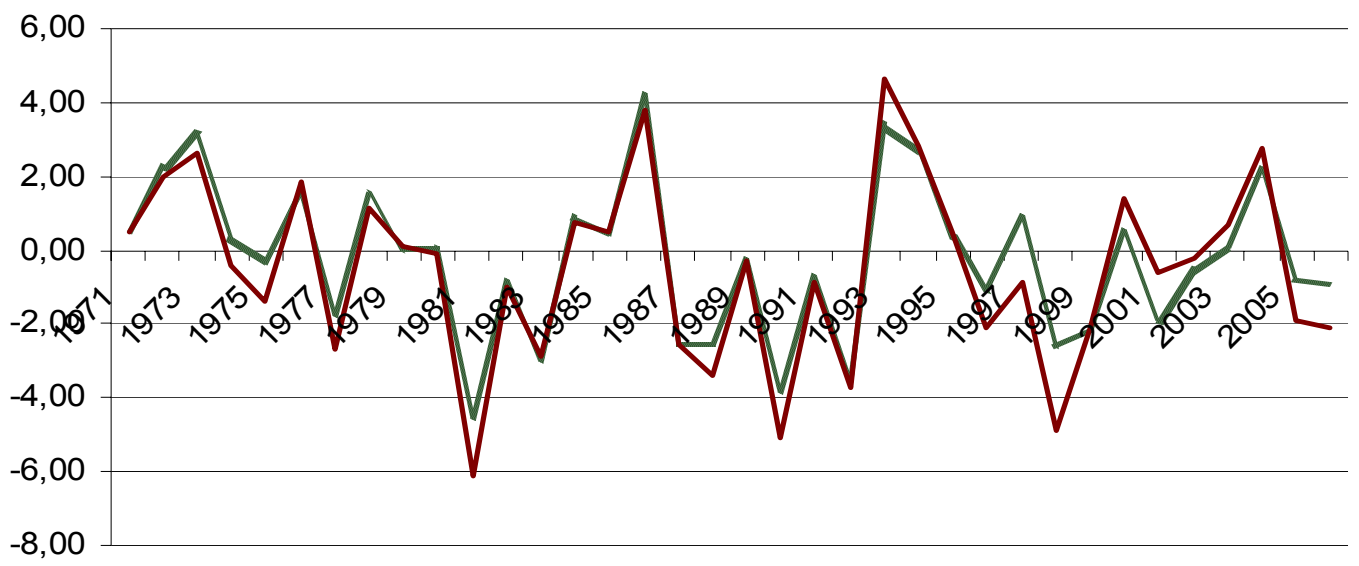

PIB - PIB INDÚSTRIA —PIB - PIB INDÚSTRIA TRANSFORMAÇÃO

Fonte: elaboração própria a partir dos dados do IBGE/SCN

Notas: as séries utilizadas são a do PIB - variação real anual - (\% a.a.) - IBGE/SCN 2000 anual, a do PIB da indústria - valor adicionado - preços básicos - variação real anual - (\% a.a.) - IBGE/SCN 2000 anual e a do PIB da indústria de transformação - valor adicionado - preços básicos - variação real anual - (\% a.a.) - IBGE/SCN 2000 anual.

Assim, os efeitos da recente valorização cambial parecem estar afetando o desempenho da indústria total e de transformação na margem, ou seja, seus efeitos só começaram a ser sentidos de uma maneira mais evidente a partir de 2005. Essa perda de participação desses setores pode ser fundamental no desempenho de longo prazo da 
economia brasileira já que são setores dinâmicos que afetam o desempenho da economia como um todo.

A importância do desenvolvimento industrial no crescimento econômico é ressaltada por diversos autores. Alguns apontam para a importância que o desenvolvimento industrial tem sobre os outros setores via efeitos de encadeamento e externalidades. Adicionalmente, o setor industrial possui um grande dinamismo e, desse modo, atua como o motor do crescimento da economia como um todo.

Murphy, Shleifer e Vishny (1989) constatam que os países que conseguiram atingir elevadas taxas de crescimento sustentável foram os mesmos que experimentaram um importante desenvolvimento industrial. Exemplos são a Grã-Bretanha no século XVIII, além de Japão e Coréia no século XX.

Os autores apontam para alguns efeitos importantes do processo de industrialização sobre o desenvolvimento econômico como economias de escala e efeitos de encadeamento com outros setores e segmentos. Um exemplo seria o aumento da demanda por bens de outros segmentos da indústria, levando a uma melhora na rentabilidade dos demais segmentos devido às economias de escala existentes nestes. Por sua vez, esse efeito elevaria ainda mais o investimento industrial, gerando, dessa forma, um círculo virtuoso de crescimento.

Outro impacto relevante da industrialização sobre o crescimento da economia como um todo é que a realização de investimentos leva a uma melhora do nível de tecnologia, como enfatizado por Kaldor (1957). Isso acontece porque, em muitos casos, há uma nova tecnologia incorporada nas novas máquinas e equipamentos e esse fenômeno é ainda mais importante no setor industrial ${ }^{13}$.

Kaldor (1957) ainda enfatiza as economias de escala dinâmicas geradas pelo setor industrial. Estas seriam o processo de aprendizado gerado na manufatura/indústria pelo ganho de experiência (learning by doing). Assim, segundo Kaldor, quanto mais rápido fosse a taxa de crescimento da produção do setor industrial, maior também seria a taxa de crescimento da produtividade nesse setor.

O fato de algumas evidências sugerirem que a elasticidade renda pelos produtos do setor industrial fosse similar ao do setor de serviços e superior ao do setor agrícola, aliada ao maior crescimento da produtividade do primeiro em relação aos demais setores devido a um

13 Keller (2004) enfatiza que tal efeito é amplificado em economias abertas, pois o comércio internacional disponibiliza bens que incorporam conhecimento externo, fornecendo tecnologia que, de outro modo, não estaria disponível ou que seria muito mais custosa para ser obtida.

36 
processo mais acentuado de learning by doing inerente a esse setor, foi outro motivo que levou Kaldor (1957) à conclusão de que o setor industrial seria o principal motor do crescimento econômico.

Os resultados de um estudo empírico para a economia mexicana realizado por Hanson (1998) apontam para a existência de importantes efeitos de encadeamento. Glaeser et al. (1992), em um estudo utilizando 170 cidades americanas, no período entre 1956 e 1987, encontram evidências da existência de externalidades dinâmicas no setor industrial. Os resultados encontrados pelos autores sugerem que quando diferentes indústrias interagem em uma mesma região geográfica ocorre a criação de um ambiente mais favorável ao surgimento de inovações. Assim, as externalidades dinâmicas na indústria são outra fonte de dinamismo para tal setor que, por sua vez, acaba refletindo no desempenho da economia como um todo.

Desse modo, como a indústria tem um maior potencial de gerar efeitos positivos sobre a economia como um todo e pelo fato dos recursos serem escassos, conforme enfatizado por Hirschman (1958), investimentos nesse setor seriam cruciais para elevar a taxa de crescimento econômico de uma maneira sustentada. Hirschman (1958) ainda sugere que seria aconselhável a realização de uma análise através do uso da matriz inversa de Leontief para identificar os setores que tenham os maiores multiplicadores de produção na economia.

Alguns estudos empíricos encontram evidências que sugerem que o desempenho do setor industrial é um elemento crucial no processo de crescimento e desenvolvimento econômico. Por exemplo, Pieper (1998), em um estudo utilizando uma série de países no período entre os anos 70 e 90, encontra evidências da existência de uma correlação positiva entre a performance do setor industrial e o desempenho da economia como um todo.

Outro estudo que encontra tal relação entre desempenho industrial e econômico foi realizado por Dasgupta e Singh (2006). Os autores encontraram resultados que indicam que o setor industrial continua a ter um papel importante no desenvolvimento econômico como preconizado por Kaldor (1957). No entanto, eles também encontraram evidências de que, atualmente, o setor de serviços está ganhando importância como um motor alternativo de crescimento econômico. Em um estudo empírico para a economia indiana, Dasgupta e Singh (2005) encontraram que os segmentos do setor de serviços que mais ganham importância como um motor alternativo do crescimento são aqueles ligados à tecnologia de informação e comunicação. 


\section{Possíveis soluções}

Dada a importância da indústria sobre o desempenho da economia como um todo e o fato de que o câmbio vem afetando de forma negativa o seu desempenho, o que poderia ser feito para que esse processo de valorização cambial seja revertido?

As soluções factíveis para reverter esse processo de valorização da taxa de câmbio só podem ser apresentadas a partir de suas causas. Soluções que não estejam relacionadas às causas desse processo são meramente paliativas.

Um bom exemplo é o acúmulo de reservas pelo Banco Central, que além de custoso pressiona a dívida interna brasileira que já se encontra em patamares assaz elevados. Outro é o apoio financeiro aos setores atingidos pela valorização do real anunciado recentemente pelo Banco Nacional de Desenvolvimento Econômico e Social (Estado de São Paulo, 2007), pois enquanto o câmbio permanecer no mesmo patamar, os recursos destinados a tais setores deverão ser contínuos para que eles possam sobreviver.

Dentre as causas da valorização citadas anteriormente, o bom desempenho do setor exportador proveniente da demanda aquecida por commodities e produtos industriais básicos pode ser contrabalançado por um aumento das importações via redução de tarifas e de outras barreiras não tarifárias, principalmente de setores que são estratégicos no processo de desenvolvimento econômico como, por exemplo, o de máquinas e equipamentos.

Essa maneira de elevar o montante de importações do país pode gerar maiores ganhos econômicos em relação ao seu aumento natural decorrente da valorização cambial, visto que não prejudica o desempenho exportador dos setores que não estão sendo beneficiados pelo aumento internacional dos preços de alguns produtos. Adicionalmente, gera uma maior margem para se estimular alguns setores chave da economia e, ao reduzir o custo de investimento destes, pode induzir a uma elevação de suas exportações.

Esta estratégia amplia ainda mais o espaço de manobra para estimular outros setores chave no dinamismo econômico. Além disso, seria uma forma de aumentar a integração econômica do Brasil com o resto do mundo, obtendo benefícios estáticos pela melhor alocação de recursos e ganhos de economia de escala, além de benefícios dinâmicos via maior especialização em alguns setores acelerando o processo de learning by doing.

Em relação aos juros, essa é uma variável chave nesse processo. Apesar da recente queda dos juros nominais (SELIC) de 12,5\% para 12\% ao ano, o diferencial em relação à taxa de juros de outros países continua sendo elevado. Assim, os ganhos de arbitragem ainda são muito altos. 
Com a continuidade desse processo, a situação cambial pode melhorar por três vias: 1) redução da entrada de divisas; 2) elevação do consumo e investimentos privados; e 3) elevação dos investimentos públicos.

A primeira via é a mais óbvia e imediata, pois ao reduzir os ganhos de arbitragem, diminui a oferta de divisas. No entanto, considerando um prazo mais longo, a redução dos juros acaba afetando a economia de outras formas. Uma delas é pela redução nos custos de investimento e dos ganhos financeiros, sendo que esses dois elementos contribuem para a canalização de recursos para investimentos produtivos. Além destes aumentarem a oferta total da economia - condição necessária para o crescimento sem inflação - também induzem ao crescimento da demanda. Portanto, levam a um crescimento das importações.

A redução dos juros também aumenta, principalmente, a demanda por bens duráveis e por imóveis, aumentando os lucros e investimentos desses segmentos da economia. Assim, esse efeito também induz a uma elevação no montante de importações.

Finalmente, por melhorar as contas do governo, libera recursos para investimentos públicos. Como já é bem sabido, o país enfrenta consideráveis gargalos ao seu crescimento sustentável, sendo dois dos principais a infra-estrutura de transporte e de energia elétrica. Investimentos nesses setores gerariam impactos sobre a demanda e, portanto, importações, além de pavimentar o caminho para o crescimento sustentado.

Em relação ao nível de Investimento Estrangeiro Direto (IED) e desvalorização do Dólar em relação às várias moedas de outros países, não há muito que se fazer. No entanto, o fluxo de IED é um elemento chave para o crescimento econômico, pois estimula a difusão e criação de tecnologia, fator chave no crescimento de longo prazo.

A mensagem é que a elevação dos preços das commodities e produtos industriais básicos com o conseqüente aumento das exportações brasileiras não é um problema a ser solucionado, mas sim uma grande oportunidade para gerar as condições que levem o país para a rota de crescimento elevado sem que a sua economia se esbarre na restrição externa.

Com um maior nível de crescimento, o problema do câmbio se resolve de forma natural sem prejudicar setores que são importantes economicamente, pois o aumento das importações será decorrência desse processo e o câmbio não permanecerá valorizado.

Para gerar um maior nível de crescimento, o nível dos juros é fundamental - apesar de não ser o único fator - pelos seus impactos sobre o nível de oferta e demanda da economia. No entanto, deixar que o câmbio permaneça em um patamar extremamente valorizado fará com que o país perca mais essa oportunidade, pois além de prejudicar alguns 
setores chaves da economia e conter as exportações destes, o aumento das importações se dará via mudança relativa de preços - o que já está ocorrendo - e não pelo crescimento econômico e conseqüente aumento da demanda interna.

Como apontado por Gala (2007): "As evidências aqui apresentadas apontam para uma recorrente subvalorização das moedas asiáticas quando comparadas às latino americanas ...”. Segundo o autor, essa diferença parece ter sido fundamental no sucesso e fracasso econômico de cada uma das regiões.

Por fim, é importante ter em mente, como já apontado, que a atual desvalorização da moeda-norte-americana e as estratégias seguidas pelos países da Ásia se constituem em elementos centrais do novo arranjo do Sistema Monetário Internacional (SMI).

Dooley, Folkerts-Landau and Garber (2003) sugerem que o atual Sistema Monetário Internacional pode ser composto por dois grandes grupos: o centro e a periferia. O centro, a economia norte-americana, possui o privilégio de emitir a moeda utilizada como reserva em nível internacional e exibe a tendência a "to live beyond its means". A periferia - formada pelo amplo conjunto de países que não possui o privilégio de emitir um padrão monetário aceito como meio de pagamento em nível internacional - encontra-se, em distintos graus, comprometida com uma estratégia do tipo export led baseada na manutenção de taxas de câmbio desvalorizadas, o que em última instância acaba promovendo, como corolário, a acumulação de reservas em dólares pelos Bancos Centrais periféricos, particularmente aqueles compromissados com esta estratégia.

Eichengreen (2004) sintetiza de forma clara como esta estratégia de export-led seguida, sobretudo pelos países da Ásia com destaque para a China geram desequilíbrio sistemáticos no SMI:

"In Addition, this new view helps us to understand how the current pattern of global imbalances arose in the first place. Asian countries have long been committed to policies of export-led growth. Pegged exchange rates and resistance to pressures for revaluation as their economies and current accounts strengthen have been at the center of their development strategies. In pursuing this approach China is following in the footsteps of newly industrializing economies of East Asia which are themselves following in the footsteps of Japan. There is no question that their accumulation of reserves is a concomitant of intervention in foreign exchange market to keep their currencies down, which is in turn a concomitant of the strategy of promoting exports as a way of stimulating growth" (Eichengreen, 2004, p.3) 
Se de um lado a estratégia asiática utiliza de forma recorrente a acumulação de reservas para manter desvalorizados os padrões monetários locais, de outro, há o interesse norte-americano de "to live beyond its means". A recorrência de déficits no saldo em transações correntes norte-americano é a materialização deste interesse norte-americano.

O Brasil, como todos sabem, seguiu ao longo dos últimos anos uma estratégia distinta permitindo que a liquidez abundante de dólares, fruto do desequilíbrio do saldo em transações correntes norte-americano, se traduzisse numa significativa valorização do Real. Permitiu-se, sobretudo a partir de 2004, que o ajuste de mercado se processasse, diferentemente do que vem ocorrendo nos países da Ásia. O fato concreto é que, igualmente distintos, vem sendo os resultados em termos de crescimento econômico do Brasil e Ásia.

\section{Referências Bibliográficas}

Dasgupta, S.; Singh, A. (2006). Manufacturing, Services and Premature Deindustrialization in Developing Countries, A Kaldorian Analysis. United Nations University Research Paper, 2006/49: 1-19.

Dasgupta, S.; Singh, A. (2005). Will Services Be the New Engine of Indian Economic Growth? Development and Change, 36 (06): 1035-58.

Dooley, M, Folkerts-Landau, D \& Garber, P. An Essay on Revived Bretton Woods System. National Bureau of Economic Research. Working Paper. N. 9971, September 2002

Eichengreen, B. Global Imbalances and The Lessons of Bretton Woods. National Bureau of Economic Research. Working Paper. N. 10497,may 2004.

Estado de São Paulo (2007). BNDES finaliza pacote de medidas. Caderno Especial Investimentos, H5, 06/06/2007.

Feijó, C. A. Carvalho, P.G.M.; Almeida, J.S.G. (2005). Ocorreu uma desindustrialização no Brasil? Texto de Discussão - Instituto de Estudos para o Desenvolvimento Industrial. Disponível em www.iedi.org.br, em 10 de junho de 2006.

Federação das Indústrias do Estado de São Paulo (FIESP). (2006). Desempenho das exportações, até quando vai o crescimento? Departamento de Pesquisas e Estudos Econômicos DEPECON, 20/09/2006.

Gala, P. (2007). Dois padrões de política cambial: América Latina e Sudeste Asiático. Economia e Sociedade, 16 (01): 65-91.

Glaeser, E.L.; Kallal, H.D.; Scheinkman, J.A.; Shleifer, A. (1992). Growth in Cities. Journal of Political Economy, 100 (6): 1126-1152.

Hanson, G.H. (1998). Regional Adjustment to Trade Liberalization. Regional Science and Urban economics, 28 (4): 419-444. University Press.

Hirschman, A. O. (1958). The strategy of economic development. New Haven:Yale

Ipeadata (2007). endereço eletrônico: www.ipeadata.gov.br. Acesso em 27/05/2007. 

591-624.

Kaldor, N. (1957). A Model of Economic Growth. The Economic Journal, 67 (268):

Keller, W. (2004). International Technology Diffusion. Journal of Economic Literature, 42 (3): 752-782.

Murphy, K.M.; Shleifer, A.; Vishny, R.W. (1989). Industrialization and the Big Push. Journal of Political Economy, 27 (5): 1003-1024.

Nakabashi, L.; Cruz, M.J.V.; Scatolin, F.D. (2007). Efeitos do Câmbio e Juros sobre as Exportações da Indústria Brasileira. Curitiba: Texto para Discussão da Universidade Federal do Paraná, 03/2007.

Palma G. (2005). Quatro fontes de desindustrialização e um novo conceito de Doença Holandesa. Trabalho apresentado na Conferência de Industrialização, Desindustrialização e Desenvolvimento, FIESP e IEDI. Centro Cultural da FIESP, 28 de Agosto de 2005.

Pieper, U. (1998). Deindustrialization and the Social and Economic Sustainability Nexus in Developing Countries: Cross-Country Evidence on Productivity and Employment. Center for Economic Policy Analysis Working Paper, 10: 1-47.

Rodrik, D. (1999). The new global economy and developing countries: making openness work. Washington: The Overseas Development Council.

Schneider, F., Frey, B. S. (1985). Economic and political determinants of foreign direct investment. World Development, 13 (2):161-175.

Scatolin, F.D.; Cruz, M.J.V.; Porcile, G.; Nakabashi, L. (2007). Desindustrialização? Uma análise comparativa entre Brasil e Paraná. Indicadores Econômicos da FEE, no prelo.

Unctad. (2003). Trade and Development Report, 2003. Disponível em www.unctad.org, em 10 de junho de 2006. 